\title{
Analysis of urban heat island movement and intensity in Tokyo metropolitan area by AMeDAS data
}

\author{
Tsuyoshi Honjo, \\ ${ }^{a}$ Graduate School of Horticulture, 648 Matsudo, Matsudo-shi, Chiba, Japan
}

\begin{abstract}
New methods of urban heat island (UHI) center/movement and usage of standard deviation (SD) of temperature for the analysis of UHI intensity (UHII) are presented in this study. UHI deviation is defined as difference between temperature of a measurement point and mean temperature of all measuring points. New definition of UHII is used as the difference between maximum and minimum UHI deviations. The UHI center is set as gravity center of relatively hot area and the movement of the UHI can be observed by the course of the center. These UHI metrics are suitable in analyzing the dense network for UHI measurement. As an application of these method, AMeDAS data is used to analyze the UHI effect in Tokyo metropolitan area (TMA) from the point of view of UHI movement and UHII. Clear difference of summer and winter pattern of the UHI in TMA was observed. In the summer pattern, the monthly average UHI area with the high UHI deviation was located from the coastal area to the north inland. About hourly change in a day, the UHI located along the coast at night and after the sunrise, the UHI gradually extended to inland. With this change, the UHI center moved from south to north and returned from north to south. In the winter pattern, the high UHI deviation area was located along the coast and the UHI center was located in the same area for all the day. The method of movement analysis is very effective to clarify the UHI characteristics of the area, especially coastal areas. The relation between the UHII and the SD of the temperature was analyzed. The UHII has strong linear relationship with the SD and the UHII is nearly four times of the SD (UHII $\cong 4 \times \mathrm{SD}$ ). Especially, in the observation of a dense network which has many measuring points, the SD is considered as more robust index of the UHII.
\end{abstract}

Key words: Measurement network, Sea-land breeze, Standard deviation, UHI center, UHI deviation

\section{Introduction}

Urban heat island (UHI) effect has been measured in many cities and its characteristics were made clear by many studies (Arnfield, 2003; Memon et al., 2009). Tokyo Metropolitan Area (TMA), which includes neighboring prefectures, is the most populated area in the world and there are many researches on the heat island of this area. (Yamashita, 1996; Ichinose et al., 1999; Kusaka et al., 2000; Kusaka, 2008; Mikami and Yamato, 2011; Yamato et al., 2017).

In the traditional UHI studies, UHI was considered as almost static and UHI intensity (UHII) was defined as temperature difference between city center and remote suburban or rural area which surround the urban area (Oke, 1973). In previous studies, the UHII was calculated from one point in the city and one point in the rural area or several points of the city center and the rural area which are chosen in the area (Kim and Baik, 2002; Memon et al., 2009). In these studies, the measurement points of the network for UHI study was relatively few. Nowadays, there are many dense networks equipped in urban area for the study of the UHI (Kim and Baik, 2005; Muller et al., 2013; Honjo et al., 2015; Hu et al., 2016; Wang et al., 2017; Yamato et al., 2017; Chen et al., 2018). In these dense networks, it is relatively easy

Received; May 30, 2018

Accepted; October 25, 2018

†Corresponding Author: honjo@faculty.chiba-u.jp

DOI: 10.2480 /agrmet.D-18-00026 to define the typical urban and rural points in inland cities (Kim and Baik, 2005; Hu et al., 2016; Wang et al., 2017) but sometimes, it is difficult to find the typical points as urban center and as rural area to measure the UHII in coastal city (Chen et al., 2018).

In the coastal cities like TMA, it is difficult to define hot city center because in the daytime, cool sea breeze blows from sea to inland (Yamato et al., 2011, 2017). Sometimes the city center do not show the highest temperature because of the influence of the cool sea breeze. In this case, the UHI dynamically moves and the shape of the UHI distribution changes according with time. The traditional UHII definition, which is temperature difference between the fixed city center point and the rural point, is not necessarily an appropriate index of the UHII.

In this study, new methods of UHI center/movement and usage of standard deviation (SD) of the temperatures for the analysis of UHII are presented. As an application of the new methods, the characteristics and the dynamic movement of the UHI in TMA was analyzed by using AMeDAS data. UHI deviation is defined as difference between temperature of a measurement point and mean temperature of all measuring points. The UHII is defined as the difference between maximum and minimum UHI deviations (hereafter, this definition is called as "max-min UHII"). The UHI center is also defined as gravity center of relatively hot area and the movement of the UHI can be observed by the course of the center. These definitions are suitable for the analysis of the dense network for the UHI measurement in the coastal area. Because the observed temperature distribution varies its shape dynamically in the dense urban network, max-min UHII 
can be one of the proper indices which represents the characteristics of the UHI in the area. In the analysis of max-min UHII, it was found that the SD of the temperature for all points show similar variation with the UHII. The SD is considered as more robust than max-min UHII if there are measurement points which show extreme high or low value. Thus, the relationship between the SD and the UHII was analyzed.

Previous studies on the distribution of UHI using AMeDAS data usually deal with short-term phenomena in summer. For the improvement, this study analyzes the distribution with the period of more than one year. By the long-term analysis and usage of new method, interesting results can be obtained about the UHI in TMA.

\section{Method}

\subsection{Analyzed area and AMeDAS data}

Analyzed area is from $35.3 \mathrm{~N}$ to $36.3 \mathrm{~N}$ degree in latitude and from 139.2E to 140.2E degrees in longitude in TMA. In the area, there are 26 measuring points of AMeDAS shown in Fig. 1. The numbers of the points are arranged according with the distance from the Tokyo (the point No. 1 of Fig. 1 which is located in Otemachi, the center of Tokyo business district).

TMA is located in Kanto Plain and the flat area of Kanto Plain is populated area and the UHI is formed. The urban area of TMA is most populated in the world and is considered as high energy-consumption area (Ichinose et al., 1999). The UHI of TMA is surrounded by rural and mountain area where the temperature is relatively cooler than the center urban area. There have been studies on the UHI of TMA by simulation (Kusaka et al., 2000; Aoyagi et al., 2012; Adachi et al., 2014; Sato et al. 2016; Ohashi et al., 2016). They use the data of AMeDAS for

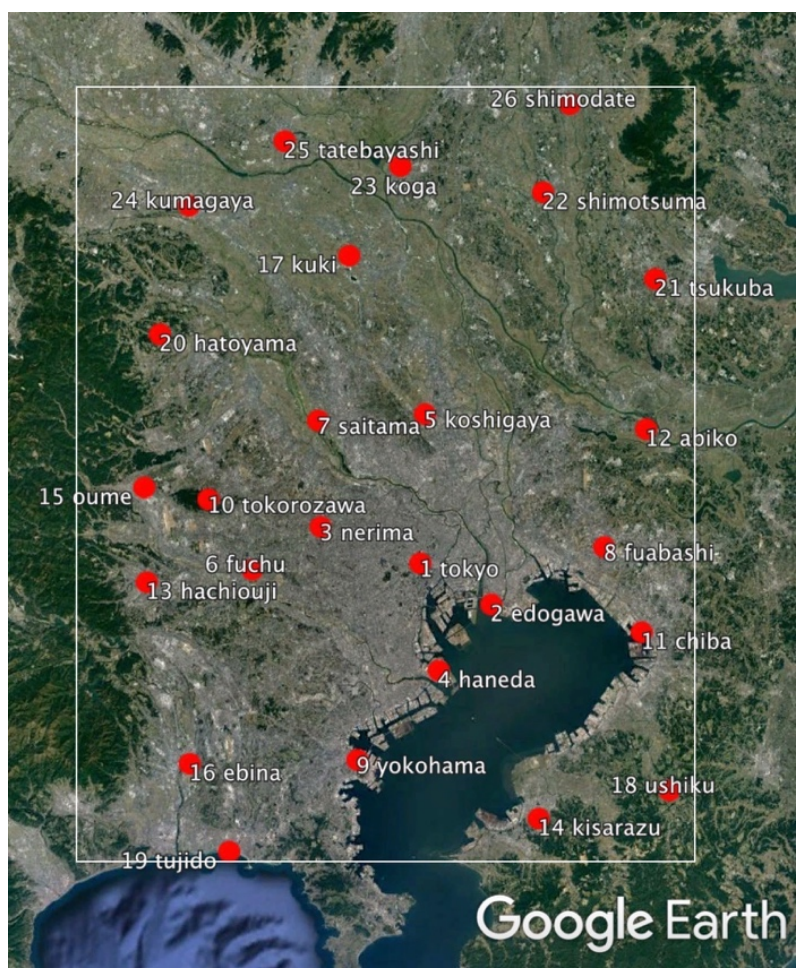

Fig. 1. Analyzed area and AMeDAS points used in this study (from $35.3 \mathrm{~N}$ to $36.3 \mathrm{~N}$ degree in latitude and from $139.2 \mathrm{E}$ to $140.2 \mathrm{E}$ degrees in longitude). the validation of the simulation.

AMeDAS data from August 2006 to September 2007 and August 2013 to September 2014 are used in the analysis. These periods are chosen because the summer UHI draw interests of us and they include typical hot summers. The data is one hour interval. Some definitions on the UHI are explained in the following sections.

\subsection{UHI deviation}

To know the characteristics of the UHI of the area, UHI deviation is defined. The UHI deviation of $i$ th point is defined as difference between temperature of point $i, t_{i}$ and mean temperature of all measuring points, $t_{\text {ave }}$. For each of measurement points, the UHI deviation, $h_{i}$ is defined as follows.

$$
\begin{aligned}
& h_{i}=t_{i}-t_{\text {ave }} \\
& t_{\text {ave }}=\frac{1}{n} \sum_{i=1}^{n} t_{i}
\end{aligned}
$$

where, $n$ is a number of all measuring points. Area of the positive UHI deviation value is considered as the UHI. To get the distribution of the UHI, the UHI deviation were interpolated by inversed distance weighing (IDW) method.

\subsection{UHI center and cool area center}

A UHI center is defined as the gravity center of the positive UHI deviation. Latitude of the UHI center, $L_{H C}$ can be calculated by following formula. Longitude of the UHI center can be also obtained with same formula.

$$
L_{H C}=\frac{\sum_{i}^{n} l_{i} \times h_{i}}{\sum_{i}^{n} h_{i}}\left(\text { if } h_{i} \geq 0 \text { then } h_{i}=h_{i} \text { else } h_{i}=0\right)
$$

where, $l_{i}$ is latitude of $i$ th observation point. If $l_{i}$ is longitude, $L_{H C}$ is longitude of the UHI center.

In the same way, it is possible to define the cool area center. The cool area center is considered to be the gravity centers of the negative UHI deviation points. Latitude of the cool area center, $L_{C C}$ can be calculated by following formula. Longitude can be also obtained with same formula.

$$
L_{C C}=\frac{\sum_{i}^{n} l_{i} \times h_{i}}{\sum_{i}^{n} h_{i}}\left(\text { if } h_{i}<0 \text { then } h_{i}=h_{i} \text { else } h_{i}=0\right)
$$

From the movement of the UHI center and the cool area center, we can know the characteristics of the UHI in TMA. They do not necessarily represent the real center of the UHI or the cool area because they are calculated as the geometrical gravity centers based on the temperatures of the existing measuring points. They are considered as the points which show the spatial characteristics of the UHI.

According with the change of the distribution of UHI, positions of the UHI center and the cool area center also change. These movements are considered as an indicator of the UHI shape or distribution change especially in the coastal cities where the shape of the UHI distribution is changed dynamically by the influence of sea-land breeze. For example, the UHI center usually moves from sea to inland according with the penetration of the sea breeze to the inland in the daytime and the cool area center shows reverse movement. 
Although the UHI center is only a spatially characteristic point, it greatly helps to understand the general position of the UHI and its movement.

\subsection{UHI Intensity}

UHII is usually defined as temperature difference between city center and rural area. But in the UHI measurement of TMA, it is difficult to find the appropriate measurement points for the representatives of the city center and the rural area because the points which show maximum or minimum temperature sometimes vary. In the dense meteorological network, one of the way to define the UHII is to use the max-min UHII expressed as follows.

\section{UHII=Maximum temperature - Minimum temperature}

The SD of the measured temperature, which is same as the SD of the UHI deviation, is also considered as one of the index for UHII, formulated as the following equation.

$$
S D=\sqrt{\frac{1}{n} \sum_{i=1}^{n}\left(t_{i}-t_{\text {ave }}\right)^{2}}
$$

In this study, the relation between the max-min UHII and the $\mathrm{SD}$ of the temperature was analyzed and effectiveness of the usage of the SD as the index of the UHII was examined. SD of the 26 points were compared with the UHII.

\section{Results}

\subsection{Temperature distribution}

Distribution maps of monthly average temperature is shown in Fig. 2. Typical summer pattern and winter pattern are seen. In the summer pattern in August, the area of high-temperature extended from the coastal area to the north inland. In the winter pattern, the high-temperature area is located along the coast and the value of the UHI deviation in coastal area is higher than that in summer pattern.
The numbers in the Fig. 2 show the monthly averaged UHI deviation and location of the UHI center. In the summer pattern, the most south center can be observed at 7:00 and it reached to the most north point at 15:00. The center moved back to the coastal area in the evening. In the winter pattern, the center located only in the coastal area and the movement was very small.

The results of 2006-7 period were same as the Fig. 2. After Fig. 3, only the results of 2013-4 period are mostly shown because the characteristics of the results are quite same for both period.

In Fig. 3, distribution of the monthly averaged UHI deviations for each hour are shown. During the measurement period, same patterns of the UHI were observed for the each hour of the months in different years.

As Fig. 2, the characteristics of the variations for each hour also had summer and winter pattern. Figure 3 a shows the typical summer pattern. The UHI locates along the coast at midnight to dawn (1:00 and 5:00 in Fig. 3a). After the sunrise, the UHI gradually extends to inland and relatively cool area was formed near the coast in the afternoon (13:00 and 17:00 in Fig. 3a). Figure $3 \mathrm{~b}$ shows the typical winter pattern and the UHI is observed along the coast for all the day. Especially, the UHII was strong at night $(21: 00,1: 00$ and 5:00 in Fig. 3b) and was relatively weak in the daytime (13:00 in Fig. 3b).

About other months, characteristics of the months were mainly classified as summer patterns and winter patterns. Intermediate transition patterns (April, October) were also observed between them.

\subsection{Hourly UHI Intensity and SD variation}

Figure 4 shows the hourly UHII and SD variation for January, 2014. In Fig. 4, the UHII and SD mostly shows similar variation. In other months, characteristics are the same. In January, the UHII was relatively higher than summer months. The minimum UHII on the day was about $2^{\circ} \mathrm{C}$ and the maximum UHII was

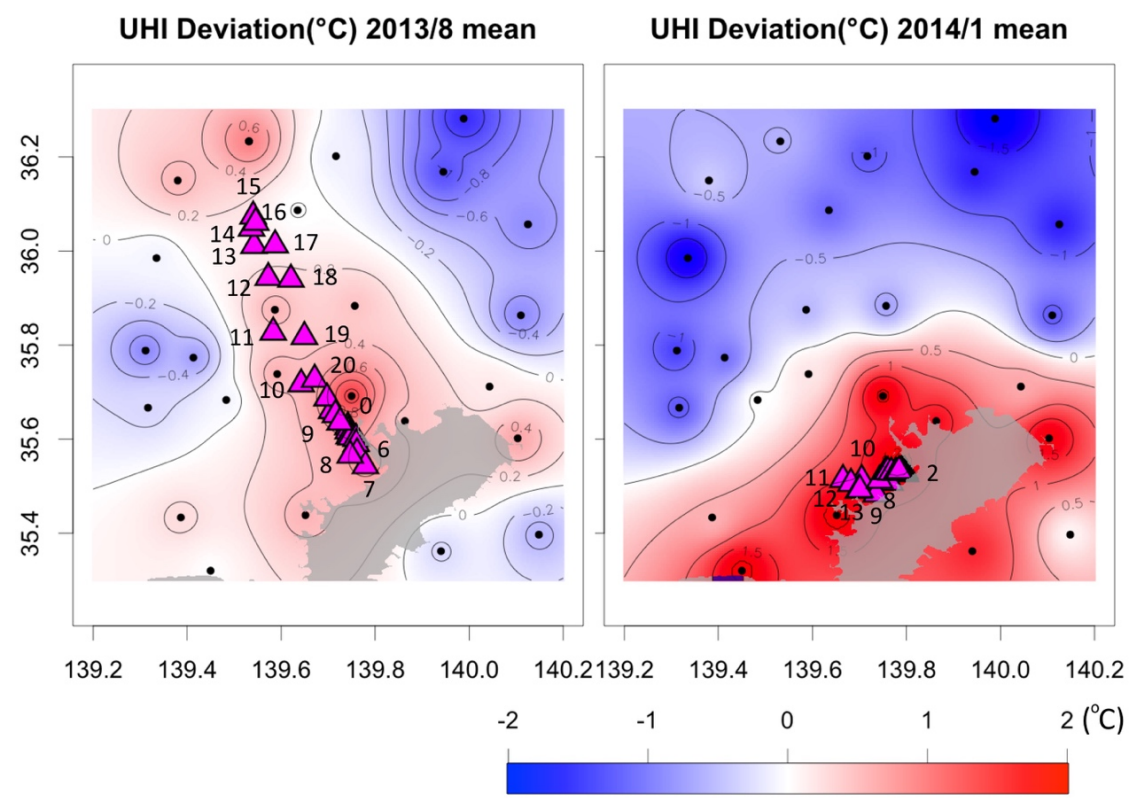

Fig. 2. Distribution maps of monthly average UHI deviation in August, 2013 and January, 2014. Typical summer pattern in August and winter pattern in January are seen. The numbers in the Fig. show the time and purple triangles mean locations of UHI center. Each center corresponds to the center of each hour shown in Fig. 3. 
(a) August, 2013

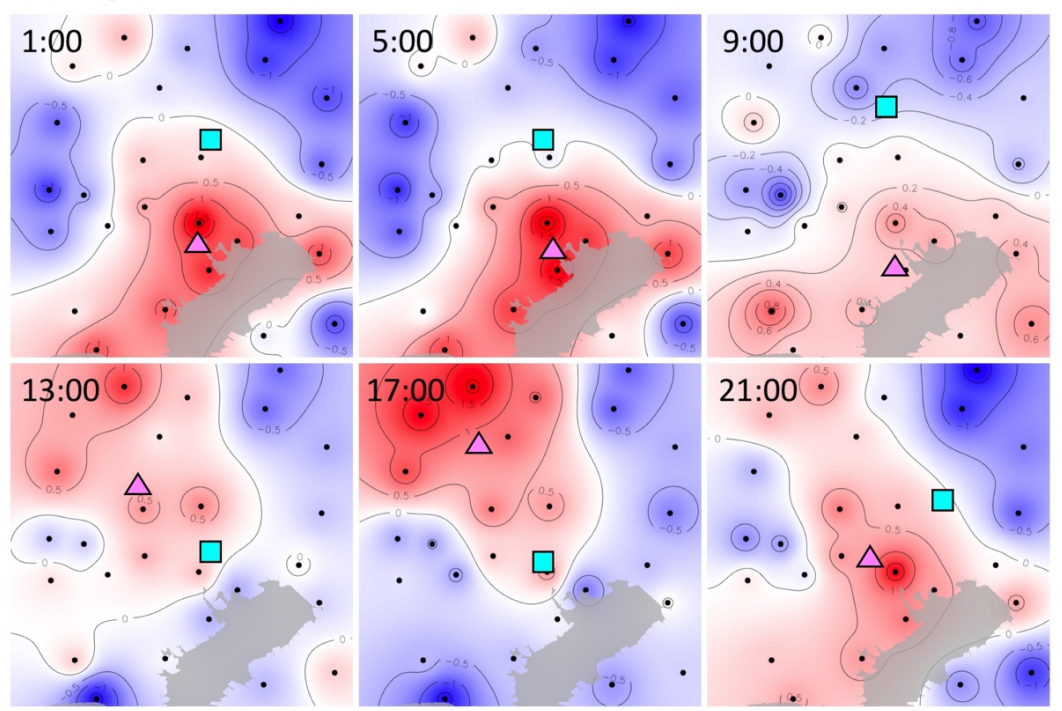

(b) January, 2014

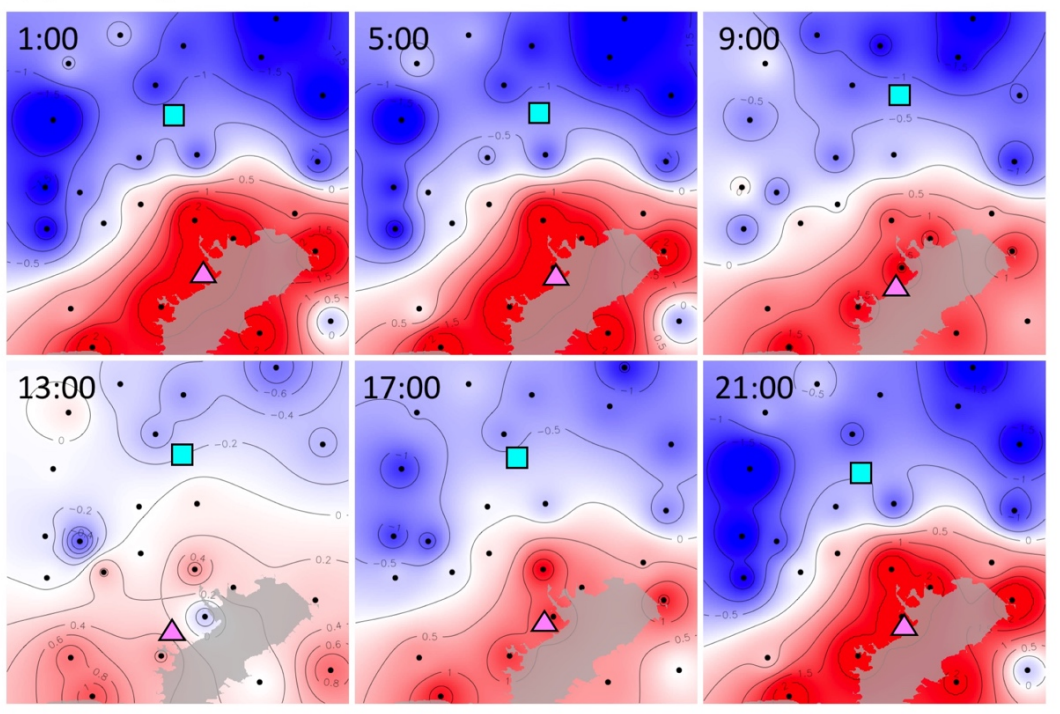

Fig. 3. Monthly average of UHI deviation for each hour in August, 2013 (a) and January, 2014 (b). Purple triangles show the location of the UHI center and cyan squares show the location of the cool area center.

mostly $10^{\circ} \mathrm{C}$. The maximum UHII reached $15^{\circ} \mathrm{C}$, which was very high value considering the size of the area.

\subsection{Daily maximum UHI Intensity and SD variation}

Figure 5 shows the daily maximum UHII and SD variation for all the analyzed period. Both periods of 2006-7 and 2013-4 show similar changes. Likes the hourly variation, the daily maximum UHII and SD show similar variation. The higher values of the UHII was mostly observed in winter months (from November to February). The lower daily maximum UHII was observed in summer months. When we focus only on the summer months from June to September, relatively higher value of UHII was observed in August.

\subsection{Correlation between UHI Intensity and SD}

The linear relation between the UHII and the SD is confirmed in Fig. 6. Hourly and daily maximum values are compared for all the analyzed period during the periods of 2006-7 and 2013-4.
The results of both periods show similar results. In the high value of the UHII (more than $10^{\circ} \mathrm{C}$ ), some points are scattered but mostly they show good correlation.

The values of coefficient in the following regression equation are also shown in Fig.6. The value of the coefficient, $a$ is nearly four for all the cases.

$$
U H I I=a \times \mathrm{SD}
$$

\subsection{The time of the maximum UHI Intensity}

In Fig. 7, the time when the daily maximum UHII was observed is shown. It is clear that there are two clusters, one in the daytime $(10: 00-18: 00)$ in summer months (from June to September) and another in the nighttime or early in the morning (21:00-7:00) in winter months (from October to March). Especially from December to March, most of the daily maximum UHII was observed in the nighttime or in the early morning. In many studies, the maximum UHII was found in the morning (Kim 

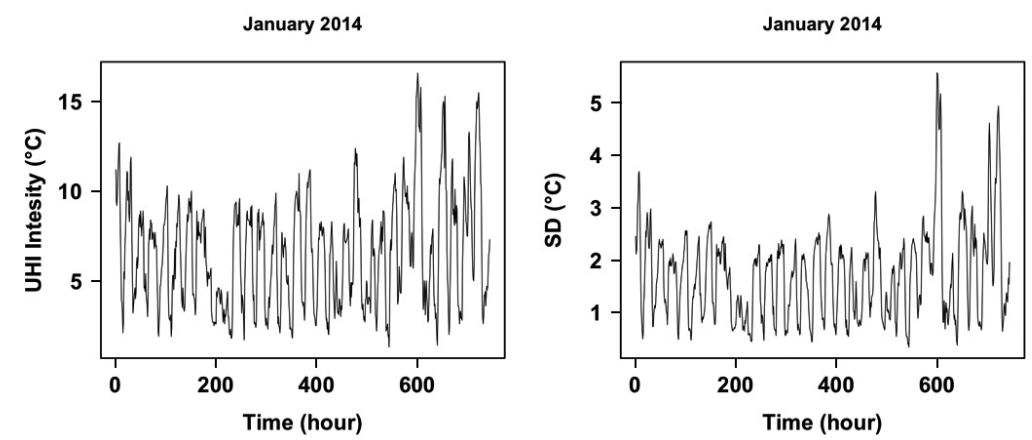

Fig. 4. Hourly UHII (left) and SD (right) variation for January, 2014.
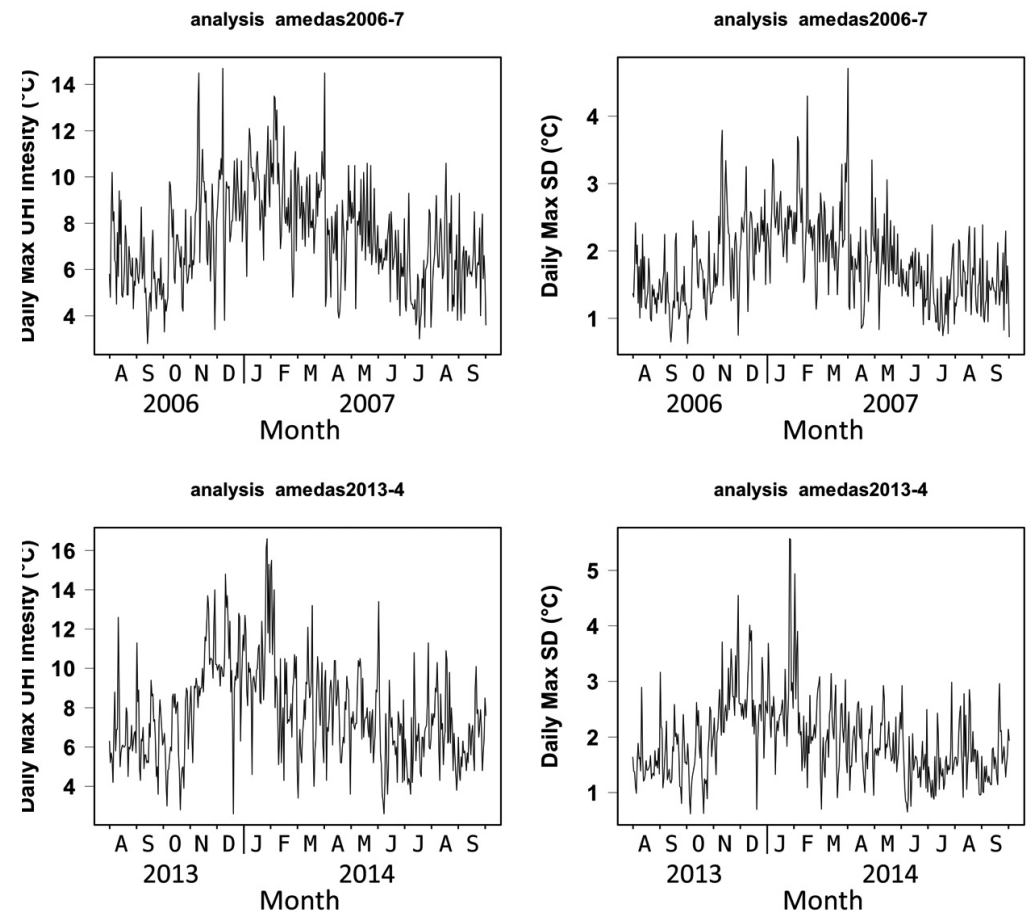

Fig. 5. Daily maximum UHII (left) and SD (right) variation for all the analyzed period.

and Baik, 2002, 2005; Memon et al., 2009). In summer months, the maximum temperature was observed in northern inland and the UHII in the daytime is stronger than that in the nighttime.

\subsection{The locations of the daily maximum UHI Intensity}

Figure 8 shows the location numbers of maximum and minimum temperature at the time when the daily maximum UHII appear in Fig. 7. The numbers of the points are arranged according with the distance from the Tokyo (No. 1).

In summer months, the location of the maximum temperature is frequently seen at Tatebayashi (No. 25) which is north inland and the location of the minimum temperature is frequently seen at Tsujido (No. 19) which is near the sea because the daily maximum UHII was observed in the afternoon when the inland is warmed and seashore is cooled by the sea wind.

In winter months, the location of the maximum temperature is mostly Haneda (No. 4) which is near the sea and the location of the minimum temperature is mostly Hatoyama (No. 20) which is north west inland. This relation is observed both in daytime and nighttime in winter. In this case, the daily maximum UHII is observed mostly at night as shown in Fig. 7.

\section{Discussion}

\subsection{UHI center and movement}

In fomer observations where the points in the city center were few, there was no choice but to consider the one of the points as the representative point of the UHI. In the dense network with many measuring points, it is difficult to find the representative point of the UHI. With the definition of the UHI center in this study, the representative point of the UHI can be objectively defined.

The UHI movement is the good indicator to explain the characteristics of the UHI in the area. In TMA, one of the important reasons for the movement can be explained by sea-land breeze (Fujibe, 2003; Yamato et al., 2011, 2017). In summer daytime, the sea breeze in TMA is relatively strong because of the large temperature difference between the sea and land. Clear effect of the cool sea wind from south Tokyo bay to the north inland of Kanto Plain can be observed in this case. Generally, this type of movements can be observed in the UHI of coastal cities.

The movement is also explained by the foehn wind in the 

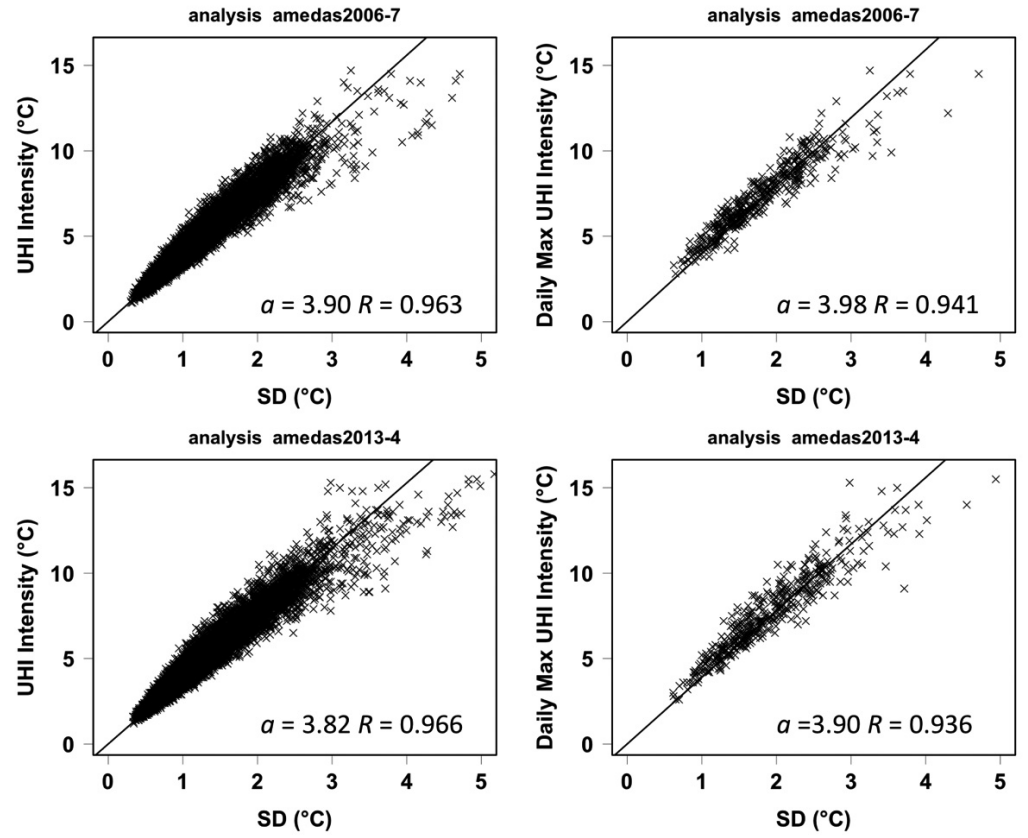

Fig. 6. Relation between the UHII and SD (left) and relation between the daily maximum UHII and SD (right) for all the analyzed period. $a$ is coefficients in $U H I I=a \times S D$ and $R$ is correlation between UHII and SD.

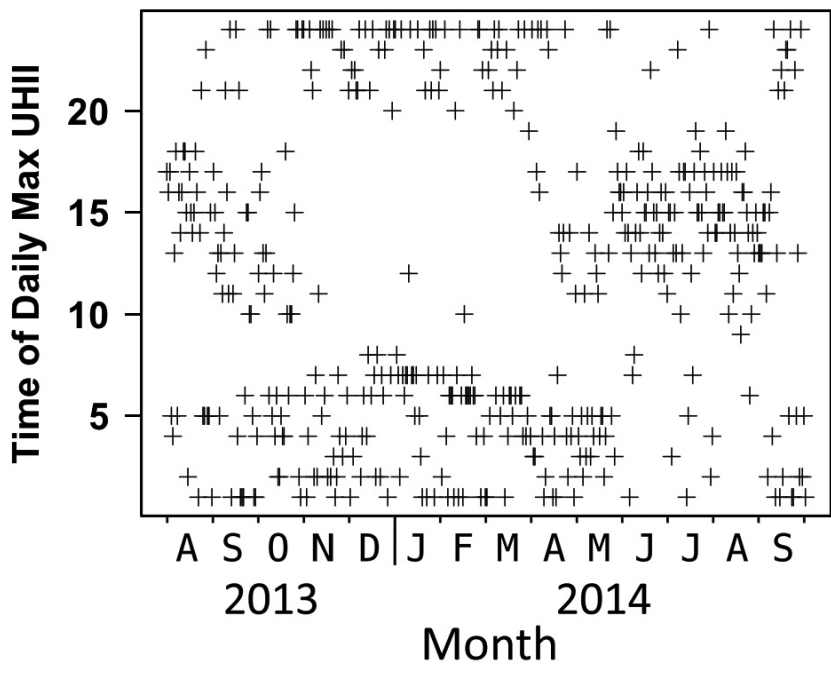

Fig. 7. The time when the daily maximum UHII was observed.

northern part of TMA. Extreme high-temperature was sometimes observed in Kumagaya and cities in the northern area of TMA by the foehn wind blowing over the Chichibu Mountains, which locates north west of TMA (Takane and Kusaka, 2011; Takane et al., 2014, 2015). The typical north-south summer movements were observed on these day. The foehn wind is also considered as one of the cause of the UHI movement in summer.

\subsection{UHI Intensity and SD}

In the measurements of dense meteorological networks with many measuring points, using max-min UHII or SD is more reasonable than selecting one city center or one representative rural point arbitrarily. Approximately, the max-min UHII is four times of the SD in many cases of the analysis by using AMeDAS data.

The coefficients of SD in the equation (7) may vary according with the distribution of the temperature in the measurement network, shape of UHI distribution, setting of measurement points etc. By comparing SDs of many cities, the UHI characteristics can be clarified in the further studies.

\subsection{Robustness of SD compared with UHI Intensity}

To show the robustness of $\mathrm{SD}$, the effect of abnormal value on the error of max-min UHII and SD is discussed in a simple case. The original data set of temperature, $t_{i}(i=1 \ldots n)$ has $n$ measurement points of data and the variance, $\sigma^{2}$ can be expressed as follows.

$$
\sigma^{2}=\frac{1}{n} \sum_{i=1}^{n}\left(t_{i}-\mu\right)^{2}=\frac{1}{n} \sum_{i=1}^{n} t_{i}^{2}-\mu^{2}
$$

where $\mu$ is average of the data set $\left(\mu=\frac{1}{n} \sum_{i=1}^{n} t_{i}\right)$.

For simplicity, we assume there is only one error in the maximum data and the error is $e_{t_{n}}$.

$$
t_{n}^{\prime}=t_{n}+e_{t_{n}}
$$

where $t_{n}^{\prime}$ is the value of the maximum data with error and the $t_{n}$ is the real value without the error. The error of the max-min UHII is also $e_{t_{n}}$. By the error, the mean of the data set become $\mu$ to $\mu^{\prime}$ with the difference, $\frac{e_{t_{n}}}{n}$.

$$
\mu^{\prime}=\mu+\frac{e_{t_{n}}}{n}
$$

The variance become $\sigma^{\prime 2}$ with the error expressed as follows.

$$
\begin{aligned}
& \sigma^{\prime 2}=\frac{1}{n}\left(\sum_{i=1}^{n-1} t_{i}{ }^{2}+t_{n}^{\prime 2}{ }^{2}\right)-\mu^{\prime 2} \\
& =\frac{1}{n}\left\{\sum_{i=1}^{n-1} t_{i}{ }^{2}+\left(t_{n}+e_{t_{n}}\right)^{2}\right\}-\left(\mu+\frac{e_{t_{n}}}{n}\right)^{2} \\
& =\sigma^{2}+\frac{2 \cdot t_{n} \cdot e_{t_{n}}}{n}+\frac{e_{t_{n}}{ }^{2}}{n}+\frac{2 \cdot \mu \cdot e_{t_{n}}}{n}+\frac{e_{t_{n}{ }^{2}}}{n^{2}}
\end{aligned}
$$


(a) Points of maximum temperature

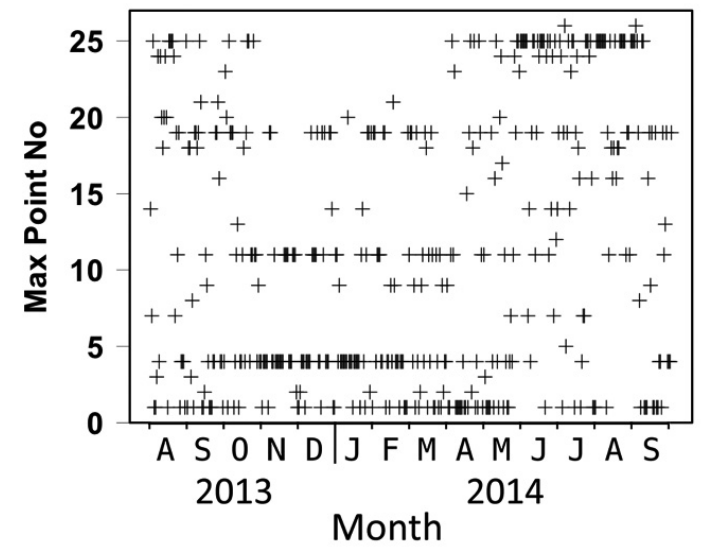

(b) Points of minimum temperature

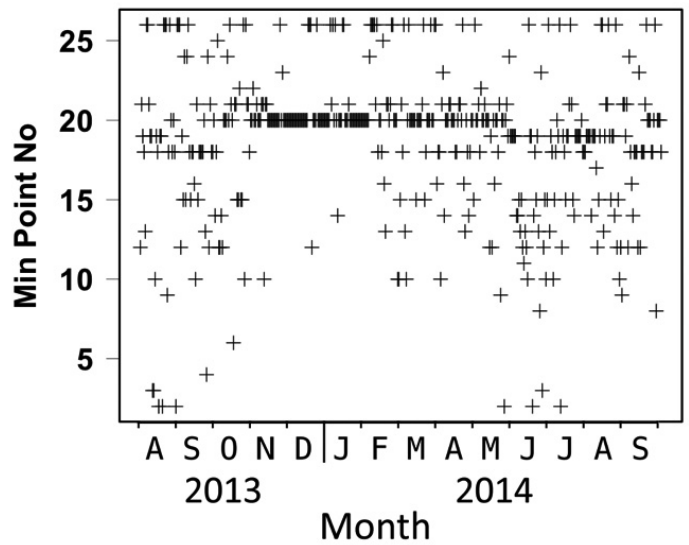

Fig. 8. Points of maximum temperature (left) and minimum (right) temperature at the time when the daily maximum UHII was recorded.

From the equation (9), we can know the difference between $\sigma^{\prime 2}$ and $\sigma^{2}$. For simplicity, we rewrite $t_{n}-\mu$ and $e_{t_{n}}$ as follows.

$$
\begin{aligned}
& t_{n}-\mu=p \cdot \sigma, \\
& e_{t_{n}}=r \cdot \sigma,
\end{aligned}
$$

where $p$ and $r$ are coefficients. For example if $\sigma=2, \mu=25, t_{n}=$ 30 , and $e_{t_{n}}=4$ then $p=2.5$ and $r=2$.

For most of the cases, we can assume $\sigma$ is less than $4^{\circ} \mathrm{C}$ from Fig. 6. Considering the distribution of temperature, $p$ is usually less than 3 . If $r$ is over 3 , we would recognize it as an abnormal value.

Then the equation (9) can be written as follow.

$$
\sigma^{\prime 2}=\sigma^{2}\left\{1+\frac{r}{n} \cdot\left(2 \cdot p+r-\frac{r}{n}\right)\right\}
$$

By using equation (10), we can define the following function, $f_{\text {err }}(n, p, r)$, which expresses the ratio of the error of $\mathrm{SD},\left(\sigma^{\prime}-\sigma\right)$, and the error of max-min UHII, $e_{t_{n}}$.

$$
f_{\text {err }}(n, p, r)=\frac{\sigma^{\prime}-\sigma}{e_{t_{n}}}=\frac{\sqrt{1+\frac{r}{n} \cdot\left(2 \cdot p+r-\frac{r}{n}\right)}-1}{r}
$$

The increase of the max-min UHII by the error, $e_{t_{n}}$ is the same as $e_{t_{n}}$. The increase of the SD by the error is $\sigma^{\prime}-\sigma$.

The variation of $f_{\text {err }}(n, p, r)$ is shown in Fig. 9. The value of $n$ varies from 1 to 100 . Only limited cases of $p=1$ or 4 and $r=1$ or 4 are shown but in the most of the cases the values are within the range of the curves of Fig. 9, if $p$ and $r$ takes the values between 1 and 4. If $p$ and $r$ are both less than 1 , the value of $f_{\text {err }}(n, p, r)$ are under the curves of Fig. 9.

Considering $a$ in the equation (7) is about 4 , the influence of the error on the SD is smaller than that of the max-min UHII when $f_{\text {err }}$ $(n, p, r)$ is less than 0.25 . Figure 9 shows $f_{\text {err }}(n, p, r)$ is less than 0.25 if $n$ is over 20 and is decreased with large $n$. This means the influence of the error on the SD is less than that on the max-min UHII. In conclusion, the SD can be considered as robust index than max-min UHII if $n$ is more than 20 in this simple case.

For the case of the minimum data, we can apply the minus value for $e_{t_{n}}$ and can have the same result.

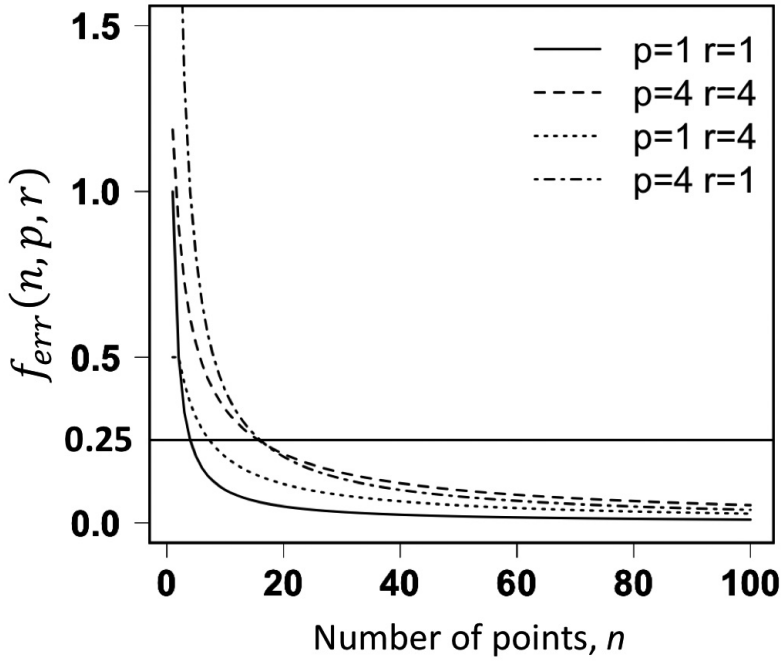

Fig. 9. Variation of $f_{\text {err }}(n, p, r)$ according with number of points, $n$. $f_{\text {err }}(n, p, r)$ expresses the relative influence of the error on SD. If the number of points is more than 20, the influence of the error on SD is considered to be small (less than 0.25) and it shows the robustness of the SD.

\section{Conclusion}

In this study, usage of the UHI center/movement, the max-min UHII and the SD is presented and effectiveness is shown for the analysis of AMeDAS data. Daily and seasonal patterns of the UHI were analyzed with the data during 2006- 7 and 2013-4 periods. About the UHI distribution in TMA, it was found that there were winter and summer patterns in many aspects. The penetration of the UHI into inland in summer and the coastal UHI in winter were typical characteristics of the UHI in TMA. The values of UHII in winter months were higher than those in summer months. The daily maximum UHII was observed in daytime in summer and in nighttime in winter.

From the analysis of the dynamic movement of the center, north-south movement of the UHI center in summer and small movement in winter were found in TMA. Dynamic difference in hourly, daily and seasonal patterns of the UHI and the 
movement of the UHI center were known. These characteristics are considered to be generally seen in many coastal cities. The method was very effective to clarify the UHI characteristics. In the further studies, the UHI center and the UHI movement proposed in this study will be applied to analyze and visualize the UHI characteristics in other UHI studies.

From the analysis of the relation between the UHII and the SD of the measured temperature, the UHII is about four times of the SD and the robustness of the SD as an index of the UHII is shown. The analysis on the relation between the UHII and SD extends the possibility of metrics of the UHII with the networks of many measurement points. By comparing the relation in many cities, the UHI characteristics can be clarified in the further studies.

\section{References}

Adachi SA, Kimura F, Kusaka H, Duda MG, Yamagata Y, Seya H, Nakamich K, Aoyagi T, 2014: Moderation of summertime heat island phenomena via modification of the Urban form in the Tokyo metropolitan area. Journal of Applied Meteorology and Climatology 53(8), 1886-1900. https://doi.org/10.1175/JAMC-D-13-0194.1

Aoyagi T, Kayaba N, Seino N, 2012: Numerical simulation of the surface air temperature change caused by increases of urban area, anthropogenic heat, and building aspect ratio in the Kanto-Koshin area. Journal of the Meteorological Society of Japan 90B, 11-31. https://doi.org/10.2151/jmsj.2012-B02

Arnfield AJ, 2003: Two decades of urban climate research: A review of turbulence, exchanges of energy and water, and the urban heat island. International Journal of Climatology 23(1), 1-26. https://doi.org/10.1002/joc.859

Chen YC, Yao CK, Honjo T, Lin TP, 2018: The application of a high-density street-level air temperature observation network (HiSAN): Dynamic variation characteristics of urban heat island in Tainan, Taiwan. Science of the Total Environment 626, 555-566. https://doi.org/10.1016/j.scitotenv.2018.01.059

Fujibe F, 2003: Long-term surface wind changes in the Tokyo metropolitan area in the afternoon of sunny days in the warm season. Journal of the Meteorological Society of Japan 81(1), 141-149. https://doi.org/Doi 10.2151/Jmsj.81.141

Honjo T, Yamato H, Mikami T, Grimmond CSB, 2015: Network optimization for enhanced resilience of urban heat island measurements. Sustainable Cities and Society 19, 319-330. https://doi.org/10.1016/j.scs.2015.02.004

$\mathrm{Hu}$ XM, Xue M, Klein PM, 2016: Analysis of urban effects in Oklahoma city using a dense surface observing network. Journal of Applied Meteorology and Climatology 55(3), 723-741. https://doi.org/10.1175/JAMC-D-15-0206.1

Ichinose T, Shimodozono K, Hanaki K, 1999: Impact of anthropogenic heat on urban climate in Tokyo. Atmospheric Environment 33(24-25), 3897-3909. https://doi.org/10.1016/S1352-2310(99)00132-6

Kim YH, Baik JJ, 2002: Maximum urban heat island intensity in Seoul. Journal of Applied Meteorology 41(6), 651-659. https:// doi.org/10.1175/1520-0450(2002)041<0651:MUHIII >2.0.CO;2

Kim YH, Baik JJ, 2005: Spatial and temporal structure of the urban heat island in Seoul. Journal of Applied Meteorology 44(5), 591-605. https://doi.org/10.1175/JAM2226.1

Kusaka H, Kimura F, Hirakuchi H, Mizutori M, 2000: The effects of land-use alteration on the sea breeze and daytime heat island in the Tokyo metropolitan area. Journal of the Meteorological Society of Japan 78(4), 405-420. https://doi.org/0026-1165

Kusaka H, 2008: Recent progress on urban climate study in Japan. Geographical Review of Japan 81(5), 361-374.

Memon RA, Leung DYC, Liu CH, 2009: An investigation of urban heat island intensity (UHII) as an indicator of urban heating. Atmospheric Research 94(3), 491-500. https://doi.org/10.1016/j.atmosres.2009.07.006

Mikami T, Yamato H, 2011: High-resolution temperature observations using extended-METROS in the Tokyo metropolitan area and their urban climatological significance. Journal of Geography (Chigaku Zasshi) 120(2), 317-324. https://doi.org/10.5026/jgeography.120.317

Muller CL, Chapman L, Grimmond CSB, Young DT, Cai X, 2013: Sensors and the city: A review of urban meteorological networks. International Journal of Climatology 33(7), 1585-1600. https://doi.org/10.1002/joc.3678

Ohashi Y, Ihara T, Kikegawa Y, Sugiyama N, 2016: Numerical simulations of influence of heat island countermeasures on outdoor human heat stress in the 23 wards of Tokyo, Japan. Energy and Buildings 114, 104-111. https://doi.org/10.1016/j.enbuild.2015.06.027

Oke TR, 1973: City size and the urban heat island. Atmospheric Environment 7(8), 769-779.

Sato Y, Higuchi A, Takami A, Murakami A, Masutomi Y, Tsuchiya K, Goto D, Nakajima T, 2016: Regional variability in the impacts of future land use on summertime temperatures in Kanto region, the Japanese megacity. Urban Forestry and Urban Greening 20, 43-55. https://doi.org/10.1016/j.ufug.2016.07.012

Takane Y, Kusaka H, 2011: Formation mechanisms of the extreme high surface air temperature of $40.9^{\circ} \mathrm{C}$ observed in the Tokyo metropolitan area: Considerations of dynamic foehn and foehnlike wind. Journal of Applied Meteorology and Climatology 50(9), 1827-1841. https://doi.org/10.1175/JAMC-D-10-05032.1

Takane Y, Kusaka H, Kondo H, 2014: Climatological study on mesoscale extreme high temperature events in the inland of the Tokyo Metropolitan Area, Japan, during the past 22 years. International Journal of Climatology 34(15), 3926-3938. https://doi.org/10.1002/joc.3951

Takane Y, Kusaka H, Kondo H, 2015: Investigation of a recent extreme high-temperature event in the Tokyo metropolitan area using numerical simulations: The potential role of a "hybrid" foehn wind. Quarterly Journal of the Royal Meteorological Society 141(690), 1857-1869. https://doi.org/10.1002/qj.2490

Wang K, Jiang S, Wang J, Zhou C, Wang X, Lee X, 2017: Comparing the diurnal and seasonal variabilities of atmospheric and surface urban heat islands based on the Beijing urban meteorological network. Journal of Geophysical Research: Atmospheres 122(4), 2131-2154. 1-24. https://doi.org/10.1002/2016JD025304

Yamashita S, 1996: Detailed structure of heat island phenomena from moving observations from electric tram-cars in metropolitan Tokyo. Atmospheric Environment 30(3), 429-435. https://doi.org/10.1016/1352-2310(95)00010-0

Yamato H, Mikami T, Takahashi H, 2011: Influence of sea breeze on the daytime urban heat island in summer in the Tokyo metropolitan area. Journal of Geography (Chigaku Zasshi) 120(2), 325-340. https://doi.org/10.5026/jgeography.120.325

Yamato H, Mikami T, Takahashi H, 2017: Impact of sea breeze penetration over urban areas on midsummer temperature distributions in the Tokyo Metropolitan area. International Journal of Climatology 37(15), 5154-5169. https://doi.org/10.1002/joc.5152 